\title{
The ways of using mother tongue in English language teaching
}

\author{
Mauro Dujmović \\ Faculty of Economics and Tourism, Juraj Dobrila University of Pula, Croatia \\ Email address: \\ mdujmov@unipu.hr
}

To cite this article:

Mauro Dujmović. The Ways of Using Mother Tongue in English Language Teaching. International Journal of Language and Linguistics. Vol. 2, No. 1, 2014, pp. 38-43. doi: 10.11648/j.jil1.20140201.15

\begin{abstract}
Humanistic views of teaching have speculated that students should be allowed to express themselves, and while they are still learning a language it is only natural that they will periodically slip back into their mother tongue, which is more comfortable for them. The support for an English-only policy has been declining recently and some researchers and teachers have begun to advocate a more bilingual approach to teaching, which would incorporate the students' L1 as a learning tool. Students will also naturally equate what they are learning with their L1 so trying to eliminate this process will only have negative consequences and impede learning. Inspired by these viewpoints and driven by my own interest, I decided to carry out a small study on the use of the mother tongue in the Croatian context. The purpose of this study was to support the fact that in the EFL classes Croatian plays only a supportive and facilitating role.
\end{abstract}

Keywords: First Language (L1), Second Language (L2), Bilingual, Monolingual, Teaching, Learning, Skills, Students, Research, Teachers

\section{Introduction}

The issue of whether or not to use the mother-tongue (L1) in the English language (L2) classroom is complex. This article presents the results of a survey into student attitudes towards the use of L1 in class and some suggestions for using the L1 and its culture as a learning resource. As in any research field, terminology can often confuse the real issue. 'Mother tongue', 'first language' and 'native language/tongue', are essentially all the same though it is possible to argue that there are instances when they mean different things. Due to the specific nature of the subjects in this research experiment (all of them are Croatian) the aforementioned terms will be used interchangeably. Majority of the students do not speak another language, and all consider Croatian as their first language native language and mother tongue. Proponents of an Englishonly policy will collectively be known as the Monolingual Approach. Those advocating the use of L1 in the classroom will be known as the Bilingual Approach. The primary goal of this paper is to find evidence to support the theory that L1 can facilitate the learning of an L2, at least in this particular situation and to demonstrate that the use of $\mathrm{L} 1$ in the classroom does not hinder learning

\section{A Short History of EFL}

A major point of debate for EFL teachers is deciding what is the right balance between using English and the use of the students' mother tongue (L1) in the classroom. While most would agree that the more English that is spoken, the quicker the students learn, arguments have also arisen to justify use of the students' native language in certain situations.

The main argument against the use of the L1 in language teaching is that students will become dependent on it, and not even try to understand meaning from context and explanation, or express what they want to say within their limited command of the target language (L2) - both of which are important skills which they will need to use when communicating in the real situation.

However, there are other, historical reasons why the use of the students' mother tongue went out of favour. Initially it was part of a reaction against the Grammar-Translation method, which had dominated late 19th and early 20th century teaching, and which saw language learning as a means towards intellectual development rather than as being for utilitarian, communicative purposes. The Direct 
Method of the early 20th century reacted against this - it aimed at oral competence and believed languages were best learnt in a way that emulated the "natural" language learning of the child - i.e. with no analysis or translation. The move away from L1 use was later reinforced by Audio-lingualism (1940s-1960s) which saw language as a matter of habit formation. The L1 was seen as a collection of already established linguistic habits which would "interfere" with the establishment of the new set of linguistic habits that constituted the target language, and was thus to be avoided at all costs. This theoretical opposition to the use of the L1 was compounded by the development of the TEFL "industry" - there are now many situations in which the teacher simply doesn't speak or even understand the students' language - for instance, teachers who move from country to country every year or so, or who are teaching multi-lingual classes in their (the teachers') own country.

In the last thirty years or so, there have continued to be some methodologies which avoid the use of the L1 - Total Physical Response is one. But others, like Suggestopaedia and Counselling Language Learning, have included it as an integral part of the methodology. Recently though support for an English-only policy has been declining, and some researchers and teachers have begun to advocate a more bilingual approach to teaching, which would incorporate the students' L1 as a learning tool. Others have even gone as far as saying the use of L1 in the classroom is necessary (Schweers, 1999, p. 6).

\section{The Role of Mother Tongue in TEFL}

Despite growing opposition to the English-only movement, its supporters remain steadfast in their determination to use English as the target language and the medium. There is some strong support for the Monolingual Approach to teaching in the literature and it could be summarized as follows:

1. The learning of an L2 should model the learning of an L1 (through maximum exposure to the L2).

2. Successful learning involves the separation and distinction of L1 and L2.

3. Students should be shown the importance of the L2 through its continual use

It is highly probable that the stigma of bilingualism in the ESL context originates from the zealous belief of the importance of English, and the disrespect shown towards other languages. English only has also come about through the blind acceptance of certain theories, which serve the interests of native speaking teachers (Weschler, 1997, p.1)

However, there is now a belief by some that the use of L1 could be a positive resource for teachers and that considerable attention and research should be focused on it.

Professionals in second language acquisition have become increasingly aware of the role the mother tongue plays in the EFL classroom. Nunan and Lamb (1996), for example, contend that EFL teachers working with monolingual students at lower levels of English proficiency find prohibition of the mother tongue to be practically impossible. Dörnyei and Kormos (1998) find that the L1 is used by L2 learners as a communication strategy to compensate for deficiencies in the target language. Richard Miles (2004) advocates the view that much of the attempt to discredit the Monolingual Approach has focused on three points: it is impractical, native teachers are not necessarily the best teachers, and exposure alone is not sufficient for learning. He thinks that monolingual teaching can also create tension and a barrier between students and teachers, and there are many occasions when it is inappropriate or impossible. When something in a lesson is not being understood and is then clarified through the use of L1 that barrier and tension can be reduced or removed.

In his work Miles quotes Phillipson and his view that the Monolingual Approach supports the idea of the native teacher as being the ideal teacher. This is certainly not the case as being a native speaker does not necessarily mean that the teacher is more qualified or better at teaching. Actually, non-native teachers are possibly better teachers as they themselves have gone through the process of learning an L2 (usually the L2 they are now teaching), thereby acquiring for themselves, an insider's perspective on learning the language. By excluding these people and their knowledge from the learning process, we are wasting a valuable resource. In addition, the term 'native teacher' is problematic. There are many variations of English around the world and as to what constitutes an authentic native English speaker, is open to endless debate. Another problem with the Monolingual Approach is its belief that exposure to language leads to learning. Excluding the students' L1 for the sake of maximizing students' exposure to the L2 is not necessarily productive.

Obviously, the quantity of exposure is important, but other factors such as the quality of the text material, trained teachers, and sound methods of teaching are more important than the amount of exposure to English.

Humanistic views of teaching have speculated that students should be allowed to express themselves, and while they are still learning a language it is only natural that they will periodically slip back into their mother tongue, which is more comfortable for them. They will also naturally equate what they are learning with their L1 so trying to eliminate this process will only have negative consequences and impede learning.

Auerbuch (1993) for example does not only acknowledges the positive role of the mother tongue in the classroom, but also identifies the following uses for it: classroom management, language analysis, presenting rules that govern grammar, discussing cross-cultural issues, giving instructions or prompts, explaining errors, and checking for comprehension.

The role of L1 in the TEFL classroom dramatically changes when you are working with people who all speak the same language. Not only will many of them have the same learning background and cultural experiences, but 
also you will find that they will make the same pronunciation errors and struggle with the same grammar challenges. This fact makes it easier to concentrate on several of their difficulties and do additional work in these areas without leaving other students out of the loop. In a situation like, this you may be able to save a great deal of time by translating a word or two. You may find yourself teaching a group of students at any level, whose previous English classes were given in L1. Here you may start out using L1 and gradually increase the use of English until your students have adjusted. In the very early stages of a beginner's class, you may find it useful to give instructions in the mother tongue or to discuss the effectiveness of a lesson or activity. In higher levels, you may still find using L1 to be a useful time saver in abstract vocabulary situation.

One of the main obstacles of having a monolingual group a teacher may face is shyness. Because they all speak the same language, they may be more self-conscious to speak to each other in English. Another problem is that they are likely to all make the same pronunciation mistakes, making it difficult for them to correct each other and possible for you to stop noticing their collective mistakes. Another challenge, especially with young learners, is to stop them from chatting in their native tongue, when they should be practicing English

The experts and numerous researchers into this field generally agree that the risk of creating L1 dependence is obviously valid, but there are also strong arguments for using the L1 if the teacher is able to do so and it could be summarized as follows:

- It can prevent time being wasted on tortuous explanations and instructions, when it could be better spent on language practice. With beginners, it may even allow the teacher to use activities which would be impossible to explain otherwise.

- It can be used contrastively to point out problem areas of grammar, false cognates etc. Various course books, like Headway, now encourage students to translate model sentences into their own language in order to compare and contrast the grammar.

- Students' receptive competence (their understanding) may be higher than their productive competence (their ability to use the language). In some circumstances the course objectives may even focus primarily on receptive competence, not expecting productive competence to reach an equivalent level - for example reading skills courses for student doctors who have to understand medical textbooks and journals in English. One way of letting students demonstrate receptive competence is by allowing them to respond using the L1. Students can also demonstrate receptive competence by discussing their understanding of a text in their L1. After reading or listening the teacher may ask them to tell what they understood (based on the pre-set task) in the L1.

- It can be used with beginners for pre-lesson small talk which allows the teacher to get to know the students as people, and for discussions to explain the course methodology etc. In addition, beginners will be less tense if they know they can at least ask for, and possibly receive, explanation in the L1.

- When students are trying to say something but having difficulty, they can say it in their own language and the teacher can reformulate it for them, possibly rephrasing and simplifying to show them how they could have expressed themselves within the language they already know.

- If the teacher does not speak the student's language, it can be useful for them (the students) to have a bilingual dictionary in the classroom so that they can double check their comprehension of lexical explanations.

- $\quad$ Some students need to combine the two languages - for example those whose jobs involve translation and interpreting. Translation is a skill which needs to be taught.

Schweers (1999) conducted a study with EFL students and their teachers in a Spanish context to investigate their attitudes toward using L1 in the L2 classroom. He found that $88.7 \%$ of Spanish students studying English wanted L1 used in the class because it facilitates learning. Students also desired up to $39 \%$ of class time be spent in L1 (Schweers, 1999, p7). Another similar research conducted by Jinlan Tang (2002) in a Chinese context showed similar results.

Inspired by these researches and driven by my own interest, I decided to carry out a similar study on the use of the native language in the Croatian context. However, there are differences between Schweer's study and this one. In Schweer's study English was the official second language of his participants, while in this study as well as in Tang's case, English was a foreign language to the participants. The participants in my research were all first-year students and the classes observed were first-year classes. Contrary to Schweer and Tang, who both included their fellow teachers in their research, my interest was primarily centred on my students' attitudes towards the use of L1.

\section{Research Design}

\subsection{Questions}

This study aimed to answer the following question: What are the attitudes of the students toward using Croatian in the EFL classroom?

\subsection{Participants}

The participants of this study were 100 first-year students attending University in Pula. Their English was at the intermediate or upper intermediate level. 


\subsection{Questionnaires}

A questionnaire (see Appendix 1) was distributed to 100 students to discover their attitudes toward using Croatian in the English classroom. The questionnaire items focused on the subjects' opinions toward the use of L1, the various occasions when they think L1 can be used, and the perceived effectiveness of L1 in their EFL classroom.

\subsection{Research Results}

Of the 100 questionnaires given to students, all were returned. The findings are presented in the following table and it should be noted that where participants could choose more than one answer to a question (items 3 and 4), totals add up to more than 100 percent.

Table 1 -Results of the questionnaire on the use of Croatian in the EFL classroom

1. Should Croatian be used in the classroom? Yes $(100 \%)$

2. Do you like your teacher to use Croatian in the class?
a. not at all $(0 \%)$
b. a little $(13 \%)$
c. sometimes $(52 \%)$
d. a lot $(32 \%)$

3. When do you think it is necessary to use Croatian in the English classroom

a. to help define some new vocabulary items (e.g., some abstract words) $(90 \%)$

b. to practice the use of some phrases and expressions $(52 \%)$

c. to explain complex grammar points $(97 \%)$

d. to explain difficult concepts or ideas (34\%)

e. to give instructions $(22 \%)$

f. to give suggestions on how to learn more effectively (27\%)

4. If you think the use of Croatian is necessary in the classroom, why?

a. It helps me to understand difficult concepts better. $(81 \%)$

b. It helps me to understand new vocabulary items better. (70\%)

c. It makes me feel at ease, comfortable and less stressed. $(36 \%)$

d. I feel less lost. (43\%)

5. Do you think the use of Croatian in the classroom helps you learn this language?

a. no $(2 \%) \quad$ b. a little $(35 \%) \quad$ c. fairly much $(25 \%) \quad$ d. a $\operatorname{lot}(38 \%)$

6. How often do you think Croatian should be used in the classroom?

$\begin{array}{lll}\text { a. never }(0 \%) & \text { b. very rarely }(11 \%) & \text { c. sometimes }\end{array}$ $(61 \%)$ d. fairly frequently $(28 \%)$

7. What percentage of the time do you think Croatian should be used in the class? Choose one.

$\begin{array}{ll}\text { Time } & \text { Answer } \\ 10 \% & 11 \% \\ 20 \% & 7 \% \\ 30 \% & 15 \% \\ 40 \% & 22 \% \\ 50 \% & 18 \% \\ 60 \% & 2 \% \\ 70 \% & 7 \% \\ 80 \% & 13 \% \\ 90 \% & 5 \%\end{array}$

The table shows that all students (100 \%) who participated in the study think that Croatian should be used in the classroom. The vast majority of students (97\%) like it when their teachers use some Croatian. According to students, Croatian was most necessary to explain complex grammar points $(97 \%)$ and to help define some new vocabulary items (90 percent). In choosing the open-ended "Other" option about when it is necessary to use Croatian in the EFL classroom, a few students indicated that the L1 could be used to translate well-written paragraphs and to compare the two languages. In explaining why they think the use of Croatian is necessary in EFL classes, the majority of student participants (81\%) indicate that it helps them to understand difficult concepts better. $70 \%$ answered that Croatian was necessary to understand new vocabulary items better. Surprising $43 \%$ of the students responded that they felt less lost. This figure is significantly smaller than the corresponding student responses in Schweer's study, in which 68.3 percent of the students preferred the use of the L1 in order to feel less lost (1999:8). A possible explanation for this difference is that the students' English language proficiency level in my study was slightly higher than in Schweer's. The few students who chose the open-ended "Other" option for why it is necessary to use the L1 indicated that Croatian could be used to understand jargon and to improve their translation ability. More than half of the students (61 percent) think Croatian should be used in the classroom "sometimes." Concerning how much time Croatian should be used in the English class, 73 percent of the students answered the amount of Croatian used should range from 10 to 50 percent of class time, and 27 percent of the students answered it should be from 60 to 90 percent of class time. The questionnaire results show that the use of Croatian language is justified in first year EFL classes. It is especially useful for language tasks such as defining vocabulary items, practicing the use of phrases and expressions, and explaining grammar rules and some important ideas. Students prefer the use of Croatian because it enhances their comprehension of new concepts and new vocabulary items and can aid comprehension.

\section{Discussion}

The results of the present study on the use of the mother tongue in a Croatian EFL context bear many similarities to Schweer's and Tang's study in a Spanish and Chinese contexts. All studies indicate that students responded positively toward its use. Minor discrepancies exist concerning the occasions when the L1 should be used. Some of these differences can be accounted for by the participants' different levels of L2 language proficiency. The students emphasized that the translation of some words, complex ideas, or even whole passages is a good way to learn a foreign language. My experience suggests that without translation, learners would be likely to make unguided and often incorrect translations. I use Croatian to 
make comprehension checks. It is important as you go along to periodically make sure students understand. I will ask, "Does everyone understand? Who can tell me the Croatian translation?" I find my students enthusiastic and receptive with respect to our classroom activities. I also feel very much in touch with them, as we share a common language when necessary. The purpose of this study was to support the fact that in the EFL classes Croatian plays only a supportive and facilitating role. The chief medium of communication in the class is still English. As with any other classroom technique, the use of the mother tongue is only a means to the end of improving foreign language proficiency. I don't agree with the majority of student participants (about 73 percent combined) that between 10 and 50 percent of class time should be spent using Croatian. In my experience 10 to $20 \%$ of time is quite enough with the percentage decreasing as the students' English proficiency increases.

\section{Conclusion}

From my own experience I can conclude that the students are highly motivated to learn English. They regard their English language as a symbol of their identity and a route to future academic and employment opportunities. Few of them feel that English is imposed on them or regard the use of English as a threat to their identity. In general students prefer greater or exclusive use of English in the classroom. In their view, Croatian should be used only when necessary to help them learn English better. I am conscious of the fact that not all EFL teachers would agree with the thesis, that L1 use in the English classroom does not hinder the learning of an L2, and can actually facilitate it. However, the bilingual / bicultural teachers are in a position to enrich the process of learning by using the mother tongue as a resource, and then, by using the L1 culture, they can facilitate the progress of their students towards the other tongue, the other culture. The research suggests and my personal experience as a learner and teacher of English as a foreign language has shown me that moderate and judicious use of the mother tongue does not reduce students' exposure to English, but rather can assist in the teaching and learning processes. The aim of this work is not to advocate the greater use of L1 in the EFL classroom but rather to clarify some misconceptions that have troubled foreign language teachers for years, such as whether they should use the mother tongue when there is a need for it and whether the often-mentioned principle of no native language in the classroom is justifiable. It is hoped that these findings will help make more people acknowledge the role of the native language in the foreign language classroom and make teachers, experienced or not, stop feeling uneasy about using L1 or permitting its use in the classroom.

\section{Appendix 1}

Student questionnaire on the use of Croatian in the EFL classroom

This questionnaire aims to find out your attitude toward using Croatian in the English classroom. Your answers will be used for research purposes only.

Thank you for your cooperation!

1. Should Croatian be used in the classroom?
a. Yes
b. No

2. Do you like your teacher to use Croatian in the class? $\begin{array}{llll}\text { a. not at all } & \text { b. a little } & \text { c. sometimes } & \text { d. a lot }\end{array}$

3. When do you think it Is necessary to use Croatian in the English classroom?

a. to help define some new vocabulary items (e.g., some abstract words)

b. to practice the use of some phrases and expressions (e.g., doing translation exercises)

c. to explain complex grammar points

d. to explain difficult concepts or ideas

e. to give instructions

f. to give suggestions on how to learn more effectively

g. other, please specify.....

4. If you think the use of Croatian is necessary in the classroom, why?

a. It helps me to understand difficult concepts better.

b. It helps me to understand new vocabulary items better.

c. It makes me feel at ease, comfortable and less stressed.

d. I feel less lost.

e. other, please specify......

5. Do you think the use of Croatian in the classroom helps you learn this language?

$\begin{array}{llll}\text { a. no } & \text { b. a little fairly much d. a lot }\end{array}$

6. How often do you think Croatian should be used in the classroom?
a. never b. very rarely
c. sometimes
d. fairly frequently

7. What percentage of the time do you think Croatian should be used in the class? Choose one.

$\begin{array}{lllll}5 \% & 10 \% & 20 \% & 30 \% & 40 \%\end{array}$

\begin{tabular}{lllll}
$50 \%$ & $60 \%$ & $70 \%$ & $80 \%$ & $90 \%$ \\
\hline
\end{tabular}

\section{References}

[1] Auerbach, E. (1993). Reexaming English only in the ESL classroom. TESOL Quarterly 27, 1, pp. 9-32.

[2] Close, R.A. (1981). English as a Foreign Language. London. George Allen \& Unwin Publishers Ltd.

[3] Dörnyei, Z. and J. Kormos. (1998). Problem-solving mechanisms in L2 communication: A psycholinguistic perspective. Studies in Second Language Acquisition, 20, 3, pp. 349-385

[4] Miles, R. (2004). Evaluating the Use of L1 in the English language Classroom. School of Humanities. Centre for English Language Studies Department of Englis University of Birmingham. 
[5] Nunan, D. and C. Lamb. (1996). The self-directed teacher. Cambridge: Cambridge University Press.

[6] Schweers, W. Jr. (1999). Using L1 in the L2 classroom. English Teaching Forum, 37, 2, pp. 6-9.

[7] Stevick,E.W. (1992).Teaching and Learning Languages. Cambridge. Cambridge University Press.
[8] Tang, J. (2002). Using L1 in the English Classroom. English Teaching Forum, 40, 1, pp. 36-44.

[9] Weschler,R. (November 1997). Uses of Japanese (L1) in the English Classroom: Introducing the Functional-Translation Method. The Internet TESL Journal, Vol. III, No. 11 